\title{
Trauma y memoria
}

\section{Trauma e memória}

\section{Trauma and memory}

\author{
Nora Merlin*
}

\begin{abstract}
RESUMEN
Para vivir es necesario olvidar lo penoso; para que ello sea posible resulta imprescindible la construcción del pasado. Aunque resulte paradójico, Freud sostiene que la única posibilidad de olvido es el recuerdo, pues éste constituye la condición que permite al aparato psíquico delimitar, recortar un pasado. De lo contrario el trauma tiende a repetirse compulsivamente, sin cesar, factor que atormenta al sujeto en un presente eterno e ilimitado. Respecto a la relación entre memoria y trauma, podemos establecer un paralelismo entre las operaciones que realiza el aparato psíquico singular y una comunidad ya que, según Freud, no hay diferencias entre los mecanismos individuales y los colectivos. Desde esta concepción, nos interesa pensar el proceso de tramitación que se produjo en la Argentina a partir de 1976, fecha en que, como sabemos, comenzó el sangriento terrorismo de Estado de la última dictadura militar. En el caso de Argentina veremos cómo se estableció allí la relación entre memoria y trauma a partir de las Madres de Plaza de Mayo y de los organismos de derechos humanos. En esta tramitación del trauma veremos surgir lo que denominamos una memoria colectiva, que constituye una nueva modalidad del amor. Habitualmente, la dimensión del amor no se incluye en la política. Sin embargo, la cultura produjo una nueva forma del amor que no puede pensarse por fuera de la política: la memoria colectiva, un amor que se hizo público.
\end{abstract}

Palabras clave: Memoria. Trauma. Terrorismo de estado. Argentina. Madres de la Plaza de Mayo.

\section{RESUMO}

Para viver é necessário esquecer o penoso. Para que isso seja possível, é imprescindível a construção do passado. Embora resulte paradoxal, Freud

* Universidad de Buenos Aires. Facultad de Psicología. Magister en Ciencia Políticas. Buenos Aires, Argentina. E-mail: noramerlin21@gmail.com. https://orcid.org/0000-0003-3466-2101. 
sustenta que a única possibilidade do esquecimento é a lembrança, pois esta constitui a condição que permite ao aparelho psíquico delimitar, recortar um passado. Caso contrário, o trauma tende a se repetir compulsivamente, sem cessar, o que atormenta o sujeito num presente eterno e ilimitado. Em relação à memória e ao trauma, podemos estabelecer um paralelismo entre as operações que realiza o aparelho psíquico singular e uma comunidade, já que, segundo Freud, não há diferenças entre os mecanismos individuais e coletivos. Desde esta concepção, interessa-nos pensar o processo de tramitação que se produziu na Argentina a partir de 1976. Nesse ano, como sabemos, começou o sangrento terrorismo de Estado da última ditadura militar. No caso da Argentina, observaremos como se estabeleceu a relação entre memória e trauma a partir das Mães da Praça de Maio e dos organismos de direitos humanos. No processo do trauma veremos surgir o que nomeamos memória coletiva, que constitui uma nova modalidade do amor. Habitualmente, a dimensão do amor não se inclui na política. No entanto, a cultura produziu uma nova forma do amor que não se pode pensar fora da política: a memória coletiva, um amor que se fez público.

Palavras-chave: Memória. Trauma. Terrorismo de Estado. Argentina. Mães da Praça de Maio.

\begin{abstract}
Living demands us to forget what is painful. For this to be possible, it is essential to build the past. Although paradoxical, Freud maintains that the only possibility of oblivion is remembering, since it constitutes the condition that allows the psychic apparatus to delimit and to cut out the past. Otherwise, trauma tends to repeat itself compulsively in an eternal present that does not cease and torments the subject. In relation to memory and trauma, we can establish a parallelism between the operations performed by the singular psychic apparatus and a community, since, according to Freud, there are no differences between individual and collective mechanisms. From this conception, we are interested in thinking about the process of proceeding that took place in Argentina from 1976 onwards, date in which, as we know, the bloody terrorism of the State in the last military dictatorship began. In the case of Argentina, we will observe how the relationship between memory and trauma was established from the Mothers of Plaza de Mayo and human rights organizations. In this process of trauma, we will see the emergence of what we call collective memory, which constitutes a new modality of love. Usually, the dimension of love is not included in politics. However, culture has produced a new form of love that cannot be conceived outside of politics: collective memory - love that has become public.
\end{abstract}

Keywords: Memory. Trauma. Terrorism of the State. Argentina. Mothers of the Plaza de Mayo. 


\section{Introducción}

Para vivir es necesario olvidar lo penoso; para que ello sea posible resulta imprescindible la construcción del pasado. Según Freud, el inconsciente responde a un funcionamiento organizado por procesos primarios. Esto supone cargas libres y móviles que se condensan y se desplazan, como también una lógica que se caracteriza por la atemporalidad, es decir, que no se rige por el tiempo cronológico propio de los procesos secundarios. Es en este sentido que lo traumático o los recuerdos intensamente cargados, como los describía Freud al comienzo de su teorización, no se desgastan por más tiempo que haya transcurrido, sino que continúan teniendo eficacia patógena. Aunque resulte paradójico, Freud sostiene que la única posibilidad de olvido es el recuerdo, pues éste constituye la condición que permite al aparato psíquico delimitar, recortar un pasado. De lo contrario el trauma tiende a repetirse compulsivamente en un eterno presente que no cesa y el sujeto permanece ubicado en la misma situación que intentaba evitar. Con Freud sucumbe la concepción del tiempo lineal y cronológico basada en un continuum. En su lugar, propone una nueva temporalidad: la retroactividad. Siendo que el pasado no es estático, pasivo, inmóvil, ni mucho menos está muerto, se lo hace existir y se lo produce por la vía del recuerdo y de la interpretación. No se trata en Freud de la memoria o el recuerdo en tanto sistema enciclopedista, retórico y congelado que supone la virtud del recordar bajo el modo de describir, acumular elementos y datos de un pasado clausurado, tampoco se trata del elogio melancólico de la tradición. Por el contrario, desde la perspectiva psicoanalítica, la memoria es más bien una operación de producción de un pasado que comporta un dinamismo actual y subversivo en relación con la pulsión de muerte, definida por Freud (1984c), en 1920, como aquello que vuelve siempre al mismo lugar, un eterno retorno de lo idéntico. Para el psicoanálisis la memoria es actual e implica un pasado que se hace carne en la experiencia, por lo que el recuerdo es recuperado en una nueva red, una nueva constelación que deviene potencia del pensamiento. Como acto, la memoria hace presente el recuerdo, el cual permite recortar un pasado, que se funda cada vez y que apunta al porvenir.

El recuerdo o la memoria y la elaboración del duelo - que conlleva otras vías de simbolización distintas del recordar - constituyen las dos operaciones psíquicas que propone Freud para que se recorte un pasado que haga posible el olvido de lo penoso. De este modo, el trauma no será una herida abierta y presente constantemente que impida la vida.

Por otra parte, tal como Freud (1984c) sostiene en "Psicología de las masas y análisis del yo", no hay diferencias entre los mecanismos individuales y los 
colectivos. Respecto a la relación entre memoria y trauma, podemos establecer un paralelismo entre las operaciones que realiza el aparato psíquico singular y una comunidad. Desde esta concepción, nos interesa pensar el proceso de tramitación colectiva que se produjo en la Argentina a partir de 1976, fecha en que, como sabemos, comenzó el sangriento terrorismo de Estado de la última dictadura militar. El llamado "Proceso de Reorganización Nacional" fue una experiencia, literalmente, del terror, por lo que tuvo valor traumático en la historia del país. Del mismo modo en que funciona el aparato psíquico singular ante lo traumático, la cultura argentina respondió y tramitó la experiencia del horror a partir del recuerdo como consigna ("recordar para no repetir") y como acción política que devino luego en una memoria colectiva. Dicha memoria permitió - y no cesa de hacerlo, tanto desde el punto de vista singular como del colectivo - la elaboración del trauma. Las demandas por la aparición de los desaparecidos con vida, la búsqueda de la verdad, la justicia, los derechos humanos, la memoria, fueron los rasgos característicos de la Argentina en su transición democrática. En una lógica de articulación de demandas se fue estableciendo una construcción y una identidad populista que dejó, como uno de sus saldos, lo que hoy conocemos como memoria colectiva.

\section{El trauma}

Finalmente, luego de algunos rodeos teóricos, en "Más allá del principio del placer", junto con la conceptualización de la pulsión de muerte, el trauma queda establecido como concepto en la teoría psicoanalítica (FREUD, 1984c). Para explicarlo, Freud utiliza allí una metáfora biológica: lo define como un peligro económico para el aparato, un cúmulo de grandes cantidades que aparecen e irrumpen sorpresivamente rompiendo la "barrera protectora" de una supuesta vesícula viviente. Dicha barrera es equivalente a la realidad psíquica establecida por Freud, también llamada memoria en otros textos. El trauma, pulsión de muerte, a partir del texto mencionado se define en relación y correspondencia con la realidad psíquica. Cuando ésta última no protege o fracasa, el trauma surge como un peligro económico para el aparato que se manifiesta sin aviso, señal ni preparación. De esta concepción se deduce la función de la memoria: recordar y recortar el pasado para evitar la presencia violenta y siniestra del trauma. Para acentuar su temporalidad disruptiva, Freud también denomina al trauma (en la "Conferencia 32") o al instante traumático, como una cantidad pulsional excesiva para el aparato psíquico, algo que sobrepasa cierto límite y, 
en tanto tal experiencia no puede ser simbolizada. El trauma, pulsión de muerte, perturbación económica, tiende a repetirse dolorosa e indefinidamente como una compulsión, un eterno retorno de lo mismo. Con esta nueva concepción, cae el principio del placer como aquel que gobierna exclusivamente lo psíquico;

En vista de estas observaciones relativas a la conducta durante la transferencia y al destino fatal de los seres humanos, osaremos suponer que en la vida anímica existe realmente una compulsión de repetición que se instaura más allá del principio del placer (FREUD, 1984c, p. 22).

¿Cómo hacer para que un trauma no retorne compulsivamente en lo psíquico, en un doloroso presente que no cesa? Para vivir es necesario el olvido y el trauma se opone a tal dimensión. Paradójicamente, el recuerdo representa la posibilidad que tiene el aparato de producir el olvido, pues aquello que se repite en acto, agieren, afirma Freud, no se recuerda: "el analizado no recuerda, en general, nada de lo olvidado y reprimido, sino que lo actúa. No lo reproduce como recuerdo, sino como acción; lo repite, sin saber, desde luego que lo hace" (FREUD, 1986d, p. 152). Para que eso doloroso no retorne como eterno presente es necesaria la realidad psíquica, la memoria.

\section{La realidad psíquica o la memoria en Freud}

El psicoanálisis aportó una nueva realidad psíquica, subjetiva y representacional; Freud también la denominó memoria inconsciente y la explicó conforme al modelo del arco reflejo. Sucintamente, estableció que de lo percibido quedan marcas en el aparato que, en un segundo tiempo, a posteriori, se significan como huellas que forman la memoria. Las marcas devienen sistemas de huellas mnémicas que se asocian por cierta legalidad regida por procesos primarios y cargas móviles que se desplazan y condensan (metonimia y metáfora, respectivamente, a partir de la lingüística) entre las huellas, las cuales se reordenan continuamente siguiendo la menor resistencia. Dichos sistemas forman la memoria, por lo que desde la teoría de Freud es posible hablar de pensamientos y de memoria inconsciente.

En la "Carta 52" de la correspondencia con Fliess, Freud explica el aparato psíquico haciendo uso de un modelo que luego, en La interpretación de los 
sueños, llamará esquema óptico (1984a). No se trata de localización anatómica sino de un modelo óptico equivalente al microscopio o la cámara de fotos, en el que las imágenes conforman puntos ideales, no reales. Este aparato supone cierto número de capas permeables a la luz, cuya refracción cambia de capa en capa y está compuesto por sistemas o instancias, sistemas $P s i$, recorridos por una excitación dentro de una determinada serie temporal y una dirección. Siguiendo el modelo del arco reflejo, Freud considera que la actividad psíquica parte de estímulos recibidos por el polo sensorial o perceptivo y termina con la respuesta en el polo motor. De las percepciones que llegan queda una huella que llamará mnémica, alteraciones permanentes cuya función es la memoria, lugar en el que se pone en juego el asunto del inconsciente. Freud concluye que memoria o representaciones y percepción se excluyen: un mismo sistema no puede conservar las alteraciones de sus elementos y, al mismo tiempo, mantenerse siempre abierto y receptivo a las nuevas ocasiones de alteración. Por lo cual, se deduce que la percepción nada conserva, sino que carece de memoria. Se establece de este modo una disyunción entre el pensamiento, la memoria, el saber y la percepción, pues para que algo pase a la memoria debe borrarse de la percepción, y viceversa.

Los sistemas de huellas mnémicas experimentan reordenamientos y trasponen la excitación momentánea del polo perceptivo a huellas permanentes que se asociarán según leyes de simultaneidad - conformando lo que luego Saussure definirá como relaciones de sincronía significante -, así como de analogía, contraste y similitud, esenciales en la función de la metáfora. Las asociaciones se realizan por facilitaciones inconscientes que siguen la menor resistencia y al hacerse conscientes no muestran cualidad sensorial alguna. Concluimos que las representaciones realizan una percepción que por definición está perdida, o que resta como imposible. Con la segunda tópica, Freud retoma este esquema, pero asocia ahora percepción a conciencia, las cuales forman el mismo sistema P-Cc, y reafirma la exclusión percepción-conciencia con respecto a los sistemas de representaciones, que constituyen sistemas separados a la vez que vinculados. Hay imposibilidad de percepción para el espacio de representación y, al mismo tiempo, la percepción está sobredeterminada por el sistema de huellas mnémicas. En su "Nota sobre la «pizarra mágica»" de 1925, observa:

He supuesto que inervaciones de investidura son enviadas y vueltas a recoger en golpes periódicos rápidos desde el interior hasta el sistema $\mathrm{P}-\mathrm{Cc}$ que es completamente permeable. Mientras el sistema permanece investido de este modo, recibe las percepciones acompañadas de conciencia y transmite la excitación hacia los sistemas mnémicos incons- 
cientes; tan pronto la investidura es retirada, se extingue la conciencia, y la operación del sistema se suspende. Sería como si el inconsciente, por medio del sistema P-Cc, extendiera al encuentro del mundo exterior unas antenas que retirara rápidamente después que estas tomaron muestras de sus excitaciones (FREUD, 1984d, p. 246).

Retomando lo dicho, las huellas mnémicas realizan una percepción que resta como imposible a la representación y que está sobre determinada al mismo tiempo por el sistema de huellas mnémicas; luego el aparato psíquico intenta poder y saber vivir con esas huellas. El pensamiento, sistema de huellas, restos de la percepción imposible, produce "lo percibido" como conjetura a posteriori. Freud descubre y establece, de este modo, lo que denomina realidad psíquica: escena de representaciones que se enlazan por falso enlace, huellas mnémicas con cargas móviles que se desplazan, condensan y descargan. En la realidad psíquica (sistemas de representaciones), se juega la memoria y el asunto del inconsciente.

\section{La función de la memoria}

Freud establece que la conciencia y la percepción están determinadas o, mejor dicho, sobre determinadas por las condensaciones de la memoria inconsciente. Se deduce que la memoria, por una parte, determina la subjetividad, mientras que, por otra, constituye una defensa contra el dolor o el terror. Cuando la realidad psíquica falla en su función de velar, aparece lo que debería permanecer oculto, algo familiar que se manifiesta como nuevo, imprevisto y siniestro: núcleo de la angustia. Si la realidad psíquica no funciona, irrumpe automáticamente una angustia que avasalla al yo y lo deja impotente, fuera de juego, produciendo una posición subjetiva de desamparo, sin Otro. Tal como hemos explicado se trata de una irrupción pulsional traumática, que produce el desarrollo de una angustia automática, que Freud define en "Inhibición síntoma y angustia": "La perturbación económica por el incremento de las magnitudes de estímulo en espera de tramitación [...] constituye, pues, el núcleo genuino del "peligro" [...]. Sobreviene la reacción de angustia" (FREUD, 1986a, p. 130).

Este estado del yo se encuentra absolutamente desamparado e indefenso, se traduce como un yo sin defensas. 


\section{El olvido supone la construcción del pasado}

Paradójicamente para el psicoanálisis, sólo el recuerdo hace posible establecer el olvido, al permitir que lo traumático deje de atormentar al sujeto en un presente eterno e ilimitado. Establecer la dimensión del olvido supone delimitar una temporalidad que constituye la posibilidad de recortar un pasado.

Muy tempranamente, en su etapa preanalítica (cuando aún no había producido teóricamente el concepto de inconsciente), Freud descubrió que las personas se enfermaban por retener, no descargar recuerdos o vivencias intensamente cargadas que, justamente por esa razón, tenían eficacia patógena. En ese momento propuso un método catártico con hipnosis, que consistía en descargar el afecto, que en la teoría psicoanalítica es cantidad y no cualidad. Este método, denominado abreactivo por Breuer y Freud, permitiría completar la reacción que no se había logrado en su momento, hacer catarsis descargando el afecto ligado a una vivencia por la vía del recuerdo y la puesta en palabras. Cuando los pacientes recordaban y hablaban de su padecimiento, los síntomas desaparecían. Por esta razón Freud llega a la conclusión de que los recuerdos intensamente cargados no se desgastan solos, no sucumben al olvido como sucede con los otros recuerdos, sino que su eficacia patógena permanece presente, a pesar del tiempo transcurrido. Sabemos - y Freud lo supo muy temprano que las personas precisan olvidar, restarle intensidad a aquello traumático que les impide vivir tranquilas y placenteramente. Ya en los primeros años de su investigación Freud sostuvo que para olvidar algo penoso era necesario, en primer lugar, enfrentarlo y recordarlo. También en esa época, afirmaba que, una vez acontecida una vivencia acompañada de un intenso afecto, el aparato ya no puede deshacerse de ella. Las personas quieren olvidar, pero no lo consiguen, intentan entonces defenderse, reprimen. En vez de resolver, la defensa agrava las cosas, pues presenta varios inconvenientes: en primer lugar, siempre falla, por lo que inevitablemente hay retorno de lo reprimido, esto es, sustituciones aparentemente alejadas de lo penoso, pero que se hallan en conexión asociativa con ello. Por esta razón, el malestar de base no se resuelve, para el aparato psíquico no hay ahorro de displacer sino, por el contrario, un gasto constante de energía implicado en mantener una defensa. En segundo lugar, como la defensa necesariamente falla y deja sin resolver el malestar de base, la muralla protectora se amplía con nuevas defensas. Esto no hace más que aumentar el problema, tanto porque hay mayores puertas de entrada a lo penoso reprimido como por lo que significa económicamente para el aparato mantener el parapeto defensivo: un gran gasto psíquico y un empobrecimiento del yo, cuya energía se encuentra concentrada en la defensa y por ende limitada para otros usos. 
Los recuerdos penosos no se desgastan ni sucumben al olvido. Siguen teniendo eficacia patógena actual, en el sentido de producir sufrimiento o malestar presente, pero lo hacen desde lo inconsciente. Es preciso aclarar que en un primer momento teórico Freud aún no contaba con su esquema del aparato psíquico y hablaba de recuerdos traumáticos, aquellos que tenían intensa carga. Prontamente, establecerá que el trauma es un resto económico, una cantidad excesiva que produce displacer, y que presenta una modalidad de aparición que es la de repetición en acto, agieren, opuesta a la lógica del recuerdo-olvido; más tarde la llamará compulsión de repetición (FREUD, 1986d, 1984d).

Con respecto a las vivencias penosas o a los traumas, para el psicoanálisis no es verosímil ni posible lo que algunos enunciados proponen: "hay que ser positivo, mirar para adelante, no ir al pasado". Desde la teoría psicoanalítica se considera que sólo el recuerdo funciona como límite divisorio de dos campos temporales: el pasado y el presente. Como ya desarrollamos, sólo el recuerdo hace posible dimensionar o recortar un pasado. Ello ofrece la posibilidad de recordar sin que implique un exceso traumático, una herida abierta y actual, como si el tiempo no hubiera transcurrido. Dicho de otra manera, para que un acontecimiento doloroso no retorne compulsiva y eternamente, para que se construya una temporalidad pasada, es necesario que esa marca se transforme y se signifique como recuerdo inscripto en la memoria. El recuerdo es una herramienta, un recurso que tiene el aparato psíquico afectado por una marca para tramitarla en lugar de padecerla. Dicha operación, producida a través de la puesta en palabras, brinda la posibilidad de debilitar la densidad de carga. De este modo, se produce y se articula un recuerdo que hace posible la vida, o que está al servicio de la vida y no de la muerte. De no existir tal tramitación, surge la pesadilla o el sueño traumático que reaparece en una repetición compulsiva y demoníaca. En estos casos el sujeto se despierta inevitablemente con angustia una y otra vez, tal como Freud (1984d) lo observó en "Más allá del principio del placer". En la teoría psicoanalítica, el aparato cuenta con una segunda operación que posibilita la tramitación de lo doloroso: la elaboración del duelo.

\section{La elaboración del duelo}

Freud (1984b), en su artículo "Duelo y melancolía", considera que el duelo surge ante la pérdida de un objeto de amor o una abstracción que se hace a veces de aquel: la patria, un ideal, etc. Las personas afectadas por este tipo de pérdidas manifiestan desinterés por el mundo, pérdida de la capacidad 
de amar, autorreproches y autocastigos. ¿Cómo se realiza la elaboración de un duelo? Ella implica un trabajo que lleva tiempo, esfuerzo y que, sólo una vez concluido, posibilita el recorte de un pasado. Dicho trabajo consiste en un paulatino desasimiento o desinvestimiento libidinal, que significa el retiro de la libido que estaba fijada al objeto perdido. Afirma Freud que esta operación se produce en el marco de un proceso que supone paciencia y esfuerzo, dado que la pérdida se elabora pieza por pieza. Esa elaboración incluye el acto de hablar y recordar, pero también los de crear, inventar (sublimar); en resumen, simbolizar. De este modo se hace posible soltar el objeto que se ha perdido pero que estaba retenido por la fijación libidinal. Un objeto que, en sentido estricto, no se terminaba de perder sino que se atesoraba como presencia actual. Una vez realizada la operación de desasimiento libidinal y elaborada la pérdida, se consigue hacer del objeto y con el objeto un pasado, un recuerdo, una memoria. En aquellos casos en que la operación de desasimiento libidinal, (la cual consiste en soltar la fijación al objeto que se lo retiene en el yo), no se logra, los duelos se convierten en patológicos o en melancolía. En estos dos casos se presentan autorreproches, autodenigración, humillación, autocastigos y masoquismo crónico. Sólo el relato, el recuerdo y la elaboración del duelo pueden liberar a las personas de las cadenas que las atan a lo doloroso y traumático como si fuera eso una presencia actual, más allá del tiempo cronológico transcurrido.

Para apoyar lo dicho, quisiera comentar parte de mi experiencia clínica con respecto al último período dictatorial argentino; mi trabajo me permitió corroborar que tanto los juicios por la verdad como los testimonios de las víctimas se inscribieron en el aparato psíquico bajo la forma de las operaciones mencionadas: recuerdo, memoria y elaboración del duelo. Juicios y testimonios implicaron, por un lado, una reparación del daño subjetivo padecido y, por otro, la posibilidad de tramitar una salida de la posición de víctima y de la satisfacción masoquista que esta posición conlleva, tal como Freud (1984d) la estableció en "El problema económico del masoquismo". En todos los casos que me tocó analizar, constaté que los juicios que condujeron al castigo de los asesinos del terrorismo de Estado y los testimonios de las víctimas tuvieron valor de acto liberador: permitieron soltar el malestar allí condensado y deshabitar la culpa de estar vivo. Los autorreproches y los autocastigos con relación a lo que sufrieron los verdugos se transformaron, o sea, fue posible ubicar o transferir la culpa donde correspondía, en los reales culpables. Todo acto subjetivo implica una operación simbólica que produce un corte, delimita un antes y un después, constituye una bisagra fundante de una posición nueva. El recuerdo, la reconstrucción del trauma y el testimonio de los sobrevivientes de aquella nefasta época, produjo en todos los casos una ganancia subjetiva, el alivio y la recuperación de la propia identidad. En sus manifestaciones singulares y colectivas, el recuerdo 
la memoria y la identidad constituyen derechos inalienables de las personas. Desarrollaremos luego el tema de la identidad populista.

A lo largo de toda su obra, Freud se preguntó qué hacer con el sufrimiento: primero con el singular y, más tarde, con el padecimiento de la humanidad en general. En su última época, en el contexto del flagelo de la Primera Guerra mundial y a la par del advenimiento del nazismo, su orientación se amplió: comenzó a preocuparse por la cultura y su malestar, la religión y la psicología de las masas. Una vez que Freud perdió la "inocencia", abandonó la concepción que sostenía que el principio del placer gobernaba el aparato psíquico. Formuló más allá del principio del placer, el masoquismo como meta, la pulsión de muerte que no cesa, el fracaso de los pactos simbólicos y de los diques culturales. En esas circunstancias, Freud se había vuelto pesimista en lo relativo a las posibilidades de resolver y limitar el problema de la agresividad humana, la guerra y la hostilidad entre semejantes.

En varios de sus artículos, Freud homologó el aparato psíquico singular con la psicología de los pueblos ${ }^{1}$, por lo que es posible deducir que el recuerdo, la memoria y la elaboración del duelo son también operaciones con las que cuenta una cultura para simbolizar el horror, el terror y la herida traumática que vuelve una y otra vez. Una clave en este sentido la encontramos en el artículo "Tótem y tabú" (1913), específicamente en el punto que desarrolla el banquete totémico (FREUD, 1986e). Freud sostiene allí que la comunidad necesita recordar el crimen cometido, pues éste tiene valor traumático. En pos de ese objetivo, toda la comunidad lleva a cabo un ritual para no repetir el asesinato del padre de la horda realizado por los hermanos. En esta fiesta ritual se mata al animal totémico sustituto del padre, luego los hermanos deben beber su sangre como modo de identificarse, entre sí y con la divinidad, y a la vez renovar el pacto consensuado entre los hermanos de no matar al padre. Esta fiesta es un deber de todos los miembros de la comunidad pero al mismo tiempo también un derecho, el cual puede pensarse como derecho al recuerdo y a la identidad.

Para ejemplificar el tratamiento que una cultura realiza frente a un trauma tomaremos el caso de Argentina y veremos cómo se estableció allí la relación entre memoria y trauma. Consideramos que el terrorismo de Estado ejecutado por la última dictadura militar, que transcurrió entre 1976 y 1983, tuvo eficacia traumática en la cultura. Se habla de terrorismo de Estado cuando la fuerza pública, en manos del Estado, mediante un sistema organizado comete crímenes contra sus ciudadanos. En nombre de la "aniquilación” de la subversión, la Junta

1 Entre otros escritos de Freud, encontramos esta analogía en "Tótem y tabú", "Moisés y la religión monoteísta", "Psicología de las masas y análisis del yo" y "El porvenir de una ilusión" (1986e, 1984c, 1986a). 
Militar que gobernó el país durante esos años utilizó toda la maquinaria estatal en su accionar: empleó el terror, negando a la población todo tipo de derechos y garantías; realizó la vejación y matanza sistemática de miles de personas, aniquilando a una cultura en sus múltiples expresiones, dejándola desvalida, desamparada e indefensa. "Llamaremos traumática a una situación de desvalimiento vivenciada" (FREUD, 1986a, p. 155). Ubicamos al terrorismo de Estado de 1976 como trauma en la cultura Argentina por su violencia, horror y por haber constituido un atentado real, simbólico e imaginario contra la subjetividad singular y colectiva. La metodología represiva empleada intentó no dejar rastros, borrar los nombres, la historia, la vida, apuntó a hacer desaparecer toda marca y recuerdo, atentó contra la memoria, esto es, la identidad. Sin embargo, como dijimos al comienzo de este trabajo con relación al aparato psíquico, nunca la represión es exitosa, pues siempre falla, ni tampoco hay crimen perfecto, en el que sea posible borrar todas las huellas; en el caso argentino, a partir de algunos detalles fue posible reconstruir el pasado.

La transición argentina hacia la democracia nos permite el análisis de las relaciones entre memoria, elaboración del duelo y trauma cultural. Durante la transición las demandas por la aparición con vida de los desaparecidos, la verdad y la justicia y luego por el derecho a la identidad, la memoria, fueron concebidas como derechos humanos y devinieron en el eje de la democratización del país. Este fenómeno político constituyó el germen de lo que paulatinamente tomaría la forma de una memoria colectiva y de una construcción de identidad popular.

\section{La transición democrática argentina}

Como mencionamos, a partir de las demandas por los derechos humanos, que comienzan a articularse en el período de la transición democrática, se fue conformando en la Argentina una identidad populista y una memoria colectiva. Landi y González Bombal (1995) señalan que, en 1982, el fracaso del gobierno militar en su intento por recuperar las Islas Malvinas desencadenó la transición hacia la democracia. A diferencia de otras transiciones latinoamericanas, la de Argentina no estuvo caracterizada por acuerdos entre los militares salientes y los partidos políticos democráticos, ni tampoco se produjo en ellas la unión de fuerzas políticas para la formación de un nuevo gobierno. La transición democrática argentina se constituyó a través de las demandas que se fueron generalizando y que reclamaban, entre otras cosas, la vuelta a las instituciones. En este período se abrió una suerte de pacto cultural entre dirigentes políticos y población, un 
acuerdo definido por la revalorización del Estado de derecho, las demandas por las libertades individuales y por aquellas que exigían que no se repitiera el trauma pasado. Landi y González Bombal sostienen que el período que va desde 1982 al año siguiente estuvo signado por la movilización de la sociedad y los partidos políticos, situación que resultó decisiva para la llegada de las elecciones en 1983. En esta etapa se produjo una recreación de la escena pública en la que se fue conformando como demanda la denominada "vuelta de la Constitución". Existían también otros reclamos y denuncias por las violaciones de los derechos humanos, que demandaban su respeto y justicia. Si en un primer momento los pedidos por los desaparecidos involucraban sólo a las personas directamente afectadas, luego de la guerra de las Malvinas y con la desarticulación del relato del poder militar tuvo lugar un cambio en la opinión pública que trajo aparejado, como efecto no calculado, la creciente articulación de demandas y su expresión generalizada. Aquí cabe destacar la labor de la Asamblea Permanente por los Derechos del Hombre (APDH), creada en 1976, que fue una autoconvocatoria de personas provenientes de diversos sectores sociales, políticos, intelectuales, sindicales y religiosos, en respuesta a la situación de violencia en aumento y al quiebre del respeto por los derechos humanos más elementales. También fue muy importante la tarea del Centro de Estudios Legales y Sociales (CELS), fundado en 1979 con el propósito de encarar acciones rápidas y decisivas para detener las graves y sistemáticas violaciones de los derechos humanos, documentar el terrorismo de Estado, proporcionar ayuda legal y asistencia a los familiares de las víctimas, especialmente en los casos de detenidos-desaparecidos. Además, en plena dictadura de Videla surgieron los organismos de derechos humanos como Madres y Abuelas de la Plaza de Mayo y Familiares. Por su parte, los artistas, "las voces morales" y las personalidades de la cultura se manifestaban también condenando las violaciones cometidas a los derechos humanos. Para la transición argentina constituyó un hecho clave que el tema de los desaparecidos se posicionara en el centro de la opinión pública, al ser visto bajo la óptica de los derechos humanos. El tiempo de reacomodación de los partidos políticos fue más lento que el de los movimientos por los derechos humanos, los cuales desempeñaron un rol determinante en el espacio público.

En la campaña de Raúl Alfonsín de 1983, se impuso como tema la intervención de la justicia en el tratamiento de las violaciones a los derechos humanos. Alfonsín, ganador de las elecciones de ese año y militante del campo de los derechos humanos, se propuso como garante del corte con el pasado. Las demandas por la aparición con vida de los desaparecidos, la justicia, la verdad y la memoria, concebidos como derechos humanos, determinaron nuevos actores políticos: los movimientos y los organismos de derechos humanos, que ganaban visibilidad a la vez que su credibilidad iba en aumento. Las imágenes de los 
desaparecidos, las fotos, los nombres, sus siluetas, ocupaban el espacio público; se llevaron a cabo festivales por la memoria, el arte y la cultura, elaborando el duelo de manera colectiva y con una concurrencia masiva. Mientras que "Las Madres" durante el Proceso militar daban vueltas solas todos los jueves alrededor de la Pirámide de Mayo, en el comienzo de la democracia los organismos de derechos humanos comenzaron a convocar anualmente el 24 de marzo al conjunto del pueblo, con el propósito de conmemorar a las víctimas y recordar el día en el que se produjo el golpe de Estado: la consigna troncal era "Recordar para no repetir". Con el apoyo social se instalaron dos principios fundamentales: verdad y justicia, demandas que todavía continúan hoy. Una nueva cultura política surgió a partir de los derechos humanos, los que a su vez se convirtieron en potencias democráticas. Durante la gestión del presidente Néstor Kirchner, el 2 de agosto de 2002 el Congreso de la Nación Argentina dictó la ley 25.633, creando el Día Nacional de la Memoria por la Verdad y la Justicia.

\section{La memoria colectiva, una nueva modalidad del amor}

Habitualmente, la dimensión del amor no se incluye en la política. Se piensa que amor y política son cuestiones distintas y por lo tanto se cree que no hay relación entre ellas. Sin embargo, nuestra cultura produjo una nueva forma del amor que no puede pensarse por fuera de la política: la memoria colectiva, un amor que se hizo público. En Argentina, decimos memoria colectiva y todos sabemos que nos referimos a la trama que se tejió con los muertos y desaparecidos por el terrorismo de Estado. En general, el amor de una madre por su hijo, el de un hijo por su padre, el de una abuela por su nieto, de una novia, etc. pertenece y se mantiene en el ámbito privado. En oposición a esta intimidad, comprobamos en relación con los muertos y aún desaparecidos por la última dictadura militar, que el amor y el recuerdo de cada familiar, de cada compañero, constituyó un tejido de uno, más uno, más uno, el cual fue construyendo una novedosa forma del lazo amoroso, en que lo privado de este sentimiento se hizo público. Al conformarse un espacio de inscripción de las huellas de todos, el amor se politizó y adquirió la forma de una memoria colectiva. De este modo, amor, memoria y política se abrazan. Freud dijo que las huellas forman la memoria y así devienen defensa contra el dolor o el terror; luego, el aparato psíquico, como también una cultura, intenta saber vivir con dichas huellas; en este sentido, política y memoria se articulan. 
La inédita modalidad del amor, motivada por los organismos de derechos humanos, afectó y transformó profundamente a la cultura argentina. El derecho a la verdad, la identidad, la restitución y la justicia forman parte de nuestro ideario popular, se constituyeron y transformaron en potencias que amplían y profundizan la democracia. Cada nueva identidad singular encontrada supone también una restitución colectiva, que repara una parte mutilada de la identidad popular.

Para finalizar, destacamos a Spinoza (1987) quien ya establecía las condiciones de un vínculo entre política y amor intelectual. En su Ética, habla de potencias del alma, pasiones alegres, entre las que menciona la generosidad, que vincula al amor. Pero sostiene que en ella no se trata de mandamientos ni de retórica moralista, sino por el contrario, de un deseo activo que incumbe la vida buena y la potencia. Esta generosidad amorosa y activa es efecto de un deseo cuyo ejercicio no implica pasiones tristes ni impotencia. La generosidad de Spinoza es una forma de amor que involucra el conocimiento, un amor intelectual del prójimo y de nosotros mismos, entendidos como una fuerza productiva de comunidad. Nuestros desaparecidos desearon un mundo más justo, la alegría de ellos era la alegría de los otros. Los genocidas del terrorismo de Estado intentaron, entre otras cosas, hacer desaparecer la vida y también su deseo. Pese a ello, con la democracia éste deseo logró inscribirse y significarse políticamente. Según Spinoza, las pasiones alegres y el encuentro con cuerpos que convienen aumentan la potencia de actuar e inducen a formar ideas comunes, las que por comunes son adecuadas. Estas nociones comunes forman la comunidad de los hombres: ellas constituyen ideas esencialmente políticas de las que derivan los afectos activos, es decir, la construcción de más comunidad. Tenemos la tarea de continuar, como afecto activo, resignificando el pasado, reconstruyéndolo constantemente como memoria actual. Esa búsqueda colectiva de significación y de construcción democrática corrobora un deseo de comunidad, teniendo en cuenta que la construcción es un camino por explorar, en el que no hay certezas ni garantías, sino que más bien configura un experimento de realismo popular.

\section{REFERENCIAS}

FREUD, S. La interpretación de los sueños: segunda parte. In: FREUD, S. Obras completas, vol. V. José L. Etcheverry (Trad.). Buenos Aires: Amorrortu, 1984a. p. 345-612.

FREUD, S. Obras completas, vol. XIV. José L. Etcheverry (Trad.). Buenos Aires: Amorrortu, 1984b. 
FREUD, S. Obras completas, vol. XVIII. José L. Etcheverry (Trad.). Buenos Aires: Amorrortu, 1984c.

FREUD, S. Obras completas, vol. XIX. José L. Etcheverry (Trad.). Buenos Aires: Amorrortu, 1984d.

FREUD, S. Inhibición, síntoma y angustia. In: FREUD, S. Obras completas, vol. XX. José L. Etcheverry (Trad.). Buenos Aires: Amorrortu, 1984e. p. 71-164.

FREUD, S. Obras completas, vol. XXI. José L. Etcheverry (Trad.). Buenos Aires: Amorrortu, 1986a.

FREUD, S. Obras completas, vol. I. José L. Etcheverry (Trad.). Buenos Aires: Amorrortu, $1986 \mathrm{~b}$.

FREUD, S. Obras completas, vol. III. José L. Etcheverry (Trad.). Buenos Aires: Amorrortu, $1986 \mathrm{c}$.

FREUD, S. Recordar, repetir y reelaborar. In: FREUD, S. Obras completas, vol. XII. José L. Etcheverry (Trad.). Buenos Aires: Amorrortu, 1986d. p. 149-157.

FREUD, S. Tótem y tabú. In: FREUD, S. Obras completas, vol. XIII. José L. Etcheverry (Trad.). Buenos Aires: Amorrortu, 1986e. p. 1-164.

LANDI, O.; GONZALEZ BOMBAL, I. Los derechos en la cultura política. In: ACUÑA, C. (Ed.). Juicio, castigos y memorias: derechos humanos y justicia en la política argentina. Buenos Aires: Nueva Visión, 1995. p. 149-192.

SPINOZA, B. Ética demostrada según el orden geométrico. Madrid: Alianza, 1987.

Texto recibido el 27 de marzo de 2018. Texto aprobado el 18 de mayo de 2018. 